\title{
Childhood adversity and risk of suicide: cohort study of 548721 adolescents and young adults in Sweden
}

\author{
Charlotte Björkenstam, 1,2,3 Kyriaki Kosidou,, 4,5 Emma Björkenstam,7
}

'Department of Epidemiology, Fielding School of Public Health, University of California, Los Angeles, CA, USA

${ }^{2}$ Department of Clinical

Neuroscience, Division of Social

Medicine, Karolinska Institutet,

Stockholm, Sweden

${ }^{3}$ Department of Sociology,

Stockholm University,

Stockholm, Sweden

${ }^{4}$ Department of Public Health Sciences, Division Public Health

Epidemiology, Karolinska Institutet, Stockholm, Sweden

${ }^{5}$ Center for Epidemiology and Community Medicine,

Stockholm County Council, Stockholm, Sweden

${ }^{6}$ Department of Community Health Sciences, Fielding

School of Public Health and

California Center for Population

Research, University of

California Los Angeles, LoS

Angeles, CA, USA

${ }^{7}$ Department of Public Health Sciences, Division Social

Medicine, Karolinska Institutet,

Stockholm, Sweden

Correspondence to:

C Björkenstam, Department

of Clinical Neuroscience,

Karolinska Institutet,

Stockholm, Sweden

charlotte.bjorkenstam@ki.se

Additional material is published

online only. To view please visit the journal online.

Cite this as: $B M J$ 2017;357:j1334 http://dx.doi.org/10.1136/bmj.j1334

\section{ABSTRACT}

OBJECTIVE

To examine the relation between childhood adversity, the role of school performance, and childhood psychopathology and the risk of suicide.

\section{DESIGN}

Cohort study of register based indicators of childhood adversity (at ages 0-14) including death in the family (suicide analysed separately), parental substance abuse, parental psychiatric disorder, substantial parental criminality, parental separation/single parent household, receipt of public assistance, and residential instability.

\section{SETTING}

Swedish medical birth register and various Swedish population based registers.

PARTICIPANTS

548721 individuals born 1987-91.

\section{MAIN OUTCOME MEASURES}

Estimates of suicide risk at ages $15-24$ calculated as incidence rate ratios adjusted for time at risk and confounders.

\section{RESULTS}

Adjusted incidence rate ratios for the relation between childhood adversity and suicide during adolescence and young adulthood ranged from 1.6 (95\% confidence interval 1.1 to 2.4$)$ for residential instability to 2.9 (1.4 to 5.9) for suicide in the family. There was a doseresponse relation between accumulating childhood adversity and risk: 1.1 (0.9 to 1.4) for those exposed to one adversity and 1.9 (1.4 to 2.5 ) and 2.6 (1.9 to 3.4) for those exposed to two and three or more adversities, respectively. The association with increased risk of suicide remained even after adjustment for school performance and childhood psychopathology.

\section{WHAT IS ALREADY KNOWN ON THIS TOPIC}

Exposure to adversity in childhood increases the risk for self harm in adolescence and young adulthood, and the risk of self harm is particularly increased in young people exposed to cumulative adversities

Whether childhood adversity is associated with an increased risk for death by suicide is less clear

\section{WHAT THIS STUDY ADDS}

Exposure to various common childhood adversities, such as parental psychiatric disorder, parental substance abuse, death in the family, and receipt of public assistance, is associated with a substantially increased risk of suicide in adolescence and young adulthood

The risk is clearly increased in young people exposed to cumulative adversities These results emphasise the importance of understanding the social mechanisms of suicide and the need for effective interventions early in life aimed at alleviating the suicide risk in disadvantaged children

\section{CONCLUSION}

Childhood adversity is a risk factor for suicide in adolescence and young adulthood, particularly accumulated adversity. These results emphasise the importance of understanding the social mechanisms of suicide and the need for effective interventions early in life, aiming to alleviate the risk in disadvantaged children.

\section{Introduction}

Despite the overall decline in suicide rates in Western countries during the past decades, there has not been a similar decline among adolescents and young adults. ${ }^{12}$ Suicide in young people is increasing ${ }^{13}$ and is ranked as one of the leading causes of death in those aged 15-29.1-4 Identification of the most likely risk factors for suicide early in life has important implications for future public health interventions. ${ }^{125}$

Established risk factors for suicide attempts and suicidal ideation during adolescence and young adulthood include childhood adversities, such as abuse and neglect ${ }^{67}$ and growing up in a dysfunctional household. ${ }^{18}$ Childhood adversity is usually denoted by a range of indicators, such as parental separation or divorce, death in the family, substance abuse and criminality in the home, childhood poverty, residential instability, and parental psychopathology. ${ }^{9}$ Few previous studies have examined single indicators and suicide risk among adolescents and young adults. ${ }^{810-12}$ Furthermore, they have used small samples, ranging from 113 to 15117 participants and have not focused specifically on childhood adversity. ${ }^{810-12}$ For example, young people who die by suicide are more likely to come from non-intact families (such as families where both biological parents are not present) although parental psychopathology is likely to confound this association. ${ }^{13}$ Other studies have found that parental psychopathology, including depression and substance abuse and antisocial behaviour, is associated with increased risk for suicide in adolescence. ${ }^{11}$ Several studies have also found loss of a parent, either to death or divorce, to be a significant risk factor for later suicide. ${ }^{10} 14$

Indicators of childhood adversity tend to occur in clusters, rather than as single events, ${ }^{91516}$ and are often inter-related. It has previously been shown that clustered indicators have a strong positive relation to suicide ideation and attempts in young adulthood. ${ }^{6717-20}$ We recently showed that exposure to childhood adversity was positively associated with the risk for intentional self harm in young adulthood, ${ }^{21}$ and the risk increased stepwise by number of accumulating indicators. We also found that childhood psychopathology and poor school performance were associated with increased risks for self harm among individuals exposed to childhood 
adversity, though adversity increased the risk for self harm independently of these factors. ${ }^{21}$

Other studies have shown that adults aged 18-69 who were exposed to cumulative indicators of childhood adversity have an increased risk for premature death in general. ${ }^{2223}$ No previous study, however, has examined the association between cumulative exposure to childhood adversity and death by suicide in adolescence and young adulthood.

We capitalised on Sweden's extensive and high quality nationwide registers to investigate the differential associations between a set of indicators for childhood adversity and the risk of suicide in late adolescence and young adulthood up to age 24 . We also examined whether the association between cumulative exposure to childhood adversity and suicide could be explained by childhood psychopathology. Given the fact that poor school performance is associated with childhood adversity ${ }^{24-26}$ and is a risk indicator for suicide, ${ }^{27}$ we also investigated whether it could contribute to any association.

\section{Methods}

\section{Study population}

The study population was defined as all individuals born in Sweden and recorded in the medical birth register in 1987-91 ( $\mathrm{n}=571797)$. This high quality register includes data on all deliveries in Sweden since 1973.28 After we excluded those who died before age 15 ( $n=4457)$, those who emigrated before age $15(n=18345)$, and those who were adopted $(\mathrm{n}=274)$, our final cohort comprised 548721 individuals.

We used the unique Swedish personal identity number ${ }^{29}$ to link information from several population based registers:

- The causes of death register comprises information on all deaths of Swedish residents since 1952 with causes of death coded according to ICD (international classification of diseases)

- The national patient register includes all individuals admitted to psychiatric or general hospitals, with complete coverage for all inpatient care since 1987 and for specialised outpatient care since $2001^{30}$

- The total enumeration income survey contains data on income and governmental benefits provided to all Swedish residents. The total population register includes information on age, sex, and place of residency ${ }^{31}$

- The longitudinal integration database for health insurance and labour market studies contains data from the labour market and from the educational and social sectors

- The register of court convictions holds information on all court convictions in Sweden for people aged 15 and older

- The national school register holds information on individual school performance (grade points by subject) for all students from the final ninth year in primary schools (when students are aged 15-16) since 1988. Private schools, which comprise just a small proportion of all Swedish schools, have been included since 1993. The quality of the data in the school register is high. ${ }^{32}$ Missing data are mostly because of lack of reporting from certain private schools. Not being registered in the school register could also be an indication that the person did her/ his compulsory schooling in special education because of cognitive difficulties.

\section{Indicators of childhood adversity}

We selected indicators of childhood adversity based on previous research showing them to have significant adverse health implications. ${ }^{933-39}$ We included seven indicators occurring between birth and age 14:

- Death in family (suicide was analysed separately): death of a parent or a sibling

- Parental substance abuse (severe, as we capture only inpatient care): at least one parent admitted to hospital with a main diagnosis for substance abuse (ICD-9: 291-292, 303-3050, 3570, 4255, 5353, 5710, 5711-5713, 6483, 6555, 9650, 9696-9697; ICD-10: E244, F10-F16, F18-F19, G312, G621, G721, I426, K292, K70, K852, K86, O354-355, P044, T40, T436, T51, Z502-503, Z714, Z721-Z722)

- Parental psychiatric disorder (severe, as we capture only inpatient care): admission of parent to hospital for psychiatric disorder (excluding disorders related to substance abuse) (ICD-9: 290-319; ICD-10: F00-F99)

- Parental criminality: a parent sentenced to prison, probation, or forensic psychiatric care

- Parental separation/single parent household: either having parents separated or living in a single parent household, or both

- Household receiving public assistance: at least one parent having received public assistance during at least one year

- Residential instability: two or more changes in place of residence.

By relying solely on register data, there were indicators of childhood adversity that we were not able to study, including abuse and neglect.

\section{Suicide}

The study participants were prospectively followed from age 15 with respect to suicide. Suicide was defined by the presence of ICD-10 codes X60-X84 or as death with undetermined intent (Y10-Y34) as the underlying cause of death in the causes of death register. The latter reduces spatial and secular trends in detecting and classifying cases of suicide where intent is indeterminable. ${ }^{40}$

\section{Covariates}

Because of known associations between immigrant status (including second generation) and mental health in the Swedish population, ${ }^{41}$ we included information on whether the parents of cohort members were born in Sweden or not. People from disadvantaged family backgrounds are more likely to experience childhood adversities than those born in more privileged families. ${ }^{42}$ Thus we included parental educational attainment and disposable income, measured when the child was aged 15. Parental educational attainment was classified into three categories: $\leq 9$ years, 10-12 years, and $\geq 13$ years. 
Disposable income was assessed with the individualised weighted average family income and categorised into quarters.

Childhood psychopathology was defined as any inpatient and/or outpatient treatment with a psychiatric diagnosis (chapter F in ICD-10) before age 15, recorded in the national patient register.

School performance was based on the grade point average from the final (ninth) year of compulsory school. The average was based on the student's 16 best subjects. The child earned 10-20 points per subject passed, yielding a total maximum grade point of 320 points. Thus, the average spanned from 10 to 20 (maximum points divided by number of subjects). We categorised it into quarters and added two separate groups for those with incomplete grades and those with missing grades. Missing values in the national school register are not random. Missing refers mainly to those who have graduated in another country and to those who, because of cognitive difficulties, did not graduate from compulsory school. ${ }^{43}$ Incomplete grades refer to instances where the students failed in one or more subjects.

We also included sex and year of birth in all analyses.

\section{Statistical analysis}

The individuals in our cohort were followed from age 15 (2002-06) until suicide, death from other causes, or to 31 December 2011-that is, until age 24 at most, depending on year of birth. We used multivariate Poisson regression analyses by aggregating number of years at risk and adjusting for potential confounders using a stepwise approach. The final multivariate model was adjusted for year of birth, sex, foreign born parent, parental educational attainment, parental income, school grades, and childhood psychopathology. We summed the total number of childhood adversities to assess accumulation of indicators in separate analyses. Three adversities or more were categorised into one group ( $\geq 3)$. In these analyses we also used a stepwise approach and present the crude and the adjusted multivariate model, in which we adjusted for year of birth, sex, foreign born parent, parental educational attainment, parental income, school grades, and childhood psychopathology.

\section{Sensitivity analyses}

Parental psychiatric disorder is a proxy for genetic liability for psychiatric disorder and could increase the risk of other childhood adversities. Thus, in secondary analyses, we excluded parental psychiatric disorder from the list of adversities and considered a confounder instead.

All statistical analyses were conducted with SAS v.9.4.

\section{Patient involvement}

No patients were involved in setting the research question or the outcome measures, nor were they involved in developing plans for design or implementation of the study. No patients were asked to advise on interpretation or writing up of results. There are no plans to disseminate the results of the research to study participants or the relevant patient community.

\section{Results}

Table 1 shows that $42 \%$ of the participants were exposed to at least one indicator of childhood adversity. The most prevalent indicators were parental separation/single parent household (29\%) and household receiving public assistance (20\%). Compared with children without any such experience, those exposed to at least one childhood adversity were more likely to perform worse in school, experience childhood psychopathology, have parents with lower levels of education and income, and have parents who were born outside of Sweden.

Table 2 shows the number of participants who had experienced the seven different indicators of childhood adversity and combinations thereof. Of the 23145 who had experienced parental criminality, 14959 (64\%) had also experienced parental substance abuse. Further, of the 108754 who had experienced receipt of public assistance 62245 (57\%) had also experienced parental separation.

During follow-up, 431 individuals in the study cohort died by suicide (81 $(18.8 \%)$ were classified as undetermined intent), corresponding to an average suicide rate of 10.6 per 100000 person years (95\% confidence interval 9.6 to 11.6) (table 3). Highest suicide rates per 100000 person years were found among those exposed to suicide in the family (34.9, 15.1 to 68.8), parental psychiatric disorder (27.8, 20.4 to 36.9), and substantial parental criminality (26.6, 20.0 to 34.5). Except for parental separation/single parent household, all childhood adversity indicators were associated with about twice the suicide risk compared with those without experience of childhood adversity, spanning from incidence rate ratio of 1.6 (95\% confidence interval 1.1 to 2.4 ) for residential instability to 2.9 (1.4 to 5.9) for suicide in the family.

We found a dose-response relation between number of childhood adversity indicators and risk for suicide. The incidence rate ratio was 1.1 (95\% confidence interval 0.9 to 1.4 ) for one adversity, 1.9 (1.4 to 2.5) for two adversities, and 2.6 (1.9 to 3.4) for three or more, after adjustment for important covariates including childhood psychopathology and school performance (table 3).

Experience of childhood psychopathology did not entail higher suicide risk compared with those without such experience (incidence rate ratio $0.8,95 \%$ confidence interval 0.4 to 1.7). Poor school performance, on the other hand, was associated with higher suicide risk. Compared with those with highest grades, students with lowest grades had twice the suicide risk (2.0, 1.4 to 2.8$)$, students with incomplete grades had over three times the risk (3.6, 2.5 to 5.3 ), and finally students with missing grades had over four times the risk (4.5, 2.7 to 7.3) (table 3).

Last, we performed sensitivity analyses in which we excluded parental psychiatric disorder from the list of childhood adversities and instead considered it a confounder. In these analyses, the association between adversities and suicide remained significant (see appendix).

\section{Discussion}

\section{Main findings}

Although previous research has shown that exposure to childhood adversity is associated with a substantial increase in the risk of suicide ideation and suicide 


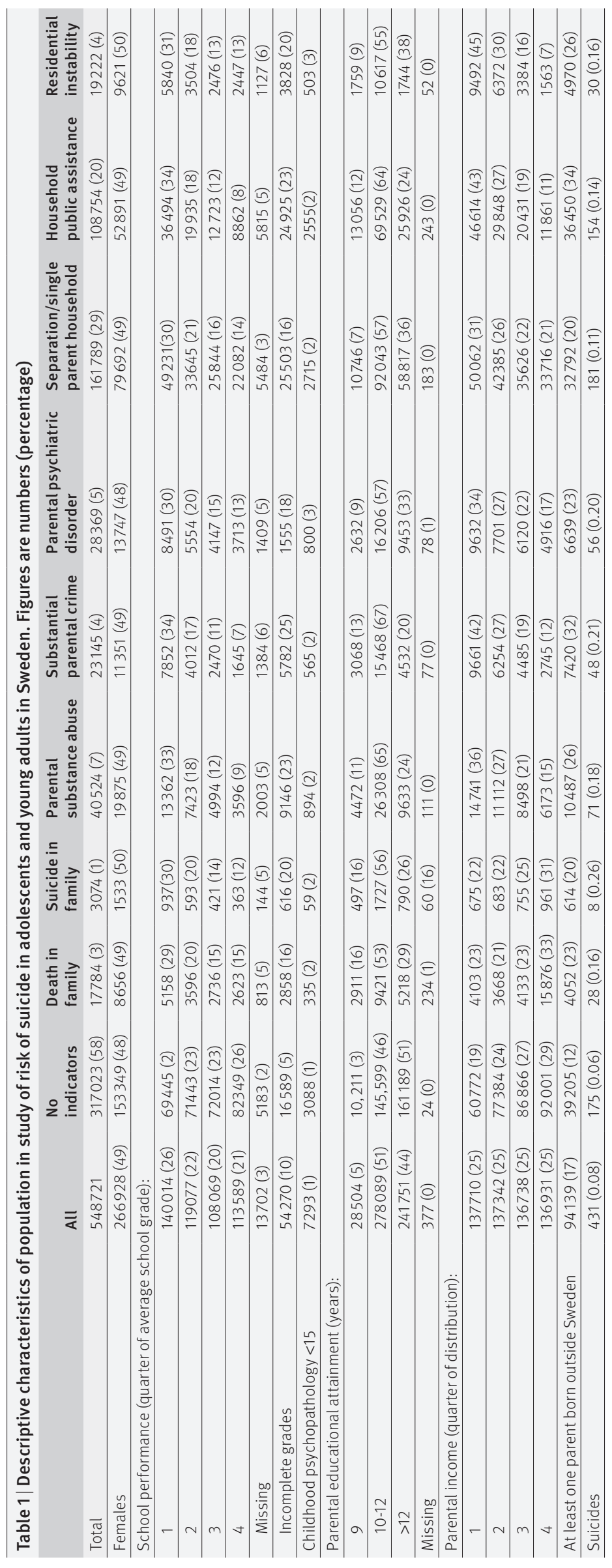

attempts as well as suicide, the association between cumulative exposure to childhood adversity and suicide risk has been less clear. ${ }^{16-844}$ Our study of 548721 individuals confirms that exposure to childhood adversity is associated with a substantially increased risk of suicide in adolescence and young adulthood and shows that the risk grows higher with increasing number of adversities. The association between adversity and suicide remained after adjustment for parental education and income, school performance, and childhood psychopathology. Exposure to suicide in the family, parental psychiatric disorder, and substantial parental criminality during childhood seem to entail greatest risks of later suicide. Moreover, childhood adversity seems to be such a strong risk factor for suicide in adolescence and young adulthood that it attenuated the effect of other known risk factors, such as poor school performance and childhood psychopathology. Childhood adversity, especially accumulated, increased the risk of suicide independently of these factors in our study.

In line with previous findings, ${ }^{394546}$ suicide in the family, parental psychiatric disorder, and parental criminality were associated with greatest suicide risk. For instance a Danish case-control study of 496 young people (aged 10-21) who died by suicide found several parental factors to be associated with an increased risk, such as parental suicide or early death, admission to hospital for a mental illness, unemployment, and low income. ${ }^{10}$

Previous studies have found a dose-response relation between childhood adversity and suicide attempts and between childhood adversity and premature death ${ }^{1622}-$ that is, the higher the number of indicators, the higher the risk. We found this to also be true for suicide mortality.

Experience of childhood adversity increases the risk for disturbed emotional and behavioural self regulation, which could increase the risk for an impulsive and destructive reaction to stress and adversities in adulthood. ${ }^{47}$ This could, at least partly, explain the relation between childhood adversity and suicide risk. Furthermore, shared environment effects such as abuse or transmission of psychopathology are other possible explanations. ${ }^{48}$ We have previously shown childhood adversity to be associated with an increased risk of self harm, ${ }^{21}$ which in turn is a strong risk factor for suicide. ${ }^{1349}$ We have also shown that young people with childhood adversity are more likely to have used psychiatric services ${ }^{50}$ compared with those without such adversity. This is probably because they have higher rates of psychiatric disorders. ${ }^{51}$ Young people exposed to childhood adversity might, nevertheless, be less likely to seek medical care when ill compared with non-exposed children, which might influence their risk of suicide. It is not known how childhood adversity might have influenced help seeking behaviour and use of psychiatric services among young people in our study.

Exposure to childhood adversity is possibly influenced by genetic factors-for example, those related to family history of suicide, parental criminality, psychiatric disorders, and substance abuse among parentswhich could also entail a higher likelihood for suicide in exposed children.52 Adjustment for parental psychiatric disorders, a proxy for children's genetic 


\begin{tabular}{|c|c|c|c|c|c|c|c|}
\hline & $\begin{array}{l}\text { Parental } \\
\text { death }\end{array}$ & $\begin{array}{l}\text { Parental } \\
\text { substance } \\
\text { abuse }\end{array}$ & $\begin{array}{l}\text { Parental } \\
\text { crime }\end{array}$ & $\begin{array}{l}\text { Parental } \\
\text { psychiatric } \\
\text { disorder }\end{array}$ & $\begin{array}{l}\text { Parental } \\
\text { separation }\end{array}$ & $\begin{array}{l}\text { Public } \\
\text { assistance }\end{array}$ & $\begin{array}{l}\text { Residential } \\
\text { instability }\end{array}$ \\
\hline Parental death & 17784 & 3582 & 1900 & 2327 & 10854 & 6500 & 1120 \\
\hline Parental substance abuse & - & 40524 & 14959 & 8281 & 22552 & 2532 & 4120 \\
\hline Parental crime & $\begin{array}{lll}- & & \\
-\end{array}$ & $\begin{array}{lll}- & & \\
-\end{array}$ & 23145 & 4077 & 13086 & 17833 & 2848 \\
\hline Parental psychiatric disorder & - & - & - & 28369 & 15519 & 15009 & 2552 \\
\hline Parental separation & - & - & - & - & 161798 & 62245 & 11146 \\
\hline Public assistance & - & - & - & - & - & 108754 & 11339 \\
\hline Residential instability & - & - & - & - & - & - & 19222 \\
\hline
\end{tabular}

Table 3 | Association between indicators of childhood adversity and suicide

\begin{tabular}{|c|c|c|c|c|c|}
\hline & \multirow{2}{*}{$\begin{array}{l}\text { No of } \\
\text { individuals }\end{array}$} & \multirow{2}{*}{$\begin{array}{l}\text { No of } \\
\text { suicides }\end{array}$} & \multirow{2}{*}{$\begin{array}{l}\text { Rates of suicide/ } \\
100000 \text { person years }\end{array}$} & \multicolumn{2}{|c|}{ Incidence risk ratio $(95 \% \mathrm{Cl})$} \\
\hline & & & & Model I* & Model II' \\
\hline All & 548721 & 431 & $10.6(9.6$ to 11.6$)$ & - & - \\
\hline No indicators & 317023 & 175 & $7.4(6.4$ to 8.6$)$ & 1 (reference) & 1 (reference) \\
\hline Death in family & 17784 & 28 & $21.0(14.0$ to 30.4$)$ & 2.1 (1.4 to 3.0$)$ & $1.9(1.3$ to 2.8$)$ \\
\hline Suicide in family & 3074 & 8 & $34.9(15.1$ to 68.8$)$ & $3.4(1.7$ to 6.7$)$ & $2.9(1.4$ to 5.9$)$ \\
\hline Parental substance abuse & 40524 & 71 & $23.6(18.4$ to 29.7$)$ & 2.5 (1.9 to 3.2$)$ & $1.9(1.4$ to 2.4$)$ \\
\hline Parental psychiatric disorder & 28369 & 48 & $27.8(20.4$ to 36.9$)$ & $2.8(2.1$ to 3.8$)$ & $2.0(1.5$ to 2.8$)$ \\
\hline Substantial parental criminality & 23145 & 56 & 26.6 (20.0 to 34.5$)$ & 2.7 (2.1 to 3.6 & $2.3(1.7$ to 3.0$)$ \\
\hline Parental separation/single parent household & 161789 & 181 & $15.1(13.0$ to 17.5$)$ & $1.7(1.4$ to 2.1$)$ & $1.4(1.2$ to 1.7$)$ \\
\hline Household receiving public assistance & 108754 & 154 & 19.1 (16.1 to 22.3$)$ & 2.3 (1.9 to 2.7$)$ & $1.6(1.3$ to 2.0$)$ \\
\hline Residential instability & 19222 & 30 & 21.0 (14.2 to 30.0$)$ & 2.1 (1.4 to 3.0) & $1.6(1.1$ to 2.4$)$ \\
\hline \multicolumn{6}{|l|}{ Year of birth: } \\
\hline 1987 & 99301 & 106 & $11.2(9.2$ to 13.5$)$ & 1 (reference) & 1 (reference) \\
\hline 1988 & 106375 & 108 & $11.9(9.8$ to 14.4$)$ & $1.1(0.8$ to 1.4$)$ & $1,1(0.8$ to 1.4$)$ \\
\hline 1989 & 109704 & 96 & 11.7 (9.5 to 14.2$)$ & $1.0(0.8$ to 1.4$)$ & $1.1(0.8$ to 1.4$)$ \\
\hline 1990 & 116329 & 64 & 8.5 (6.6 to 10.7$)$ & 0.8 (0.6 to 1.1$)$ & 0.8 (0.6 to 1.1$)$ \\
\hline 1991 & 117012 & 57 & 8.8 (6.8 to 11.4) & 0.8 (0.6 to 1.1) & $0.8(0.6$ to 1.2$)$ \\
\hline \multicolumn{6}{|l|}{ Foreign born parent: } \\
\hline No & 454582 & 341 & $10.9(9.3$ to 11.0$)$ & 1 (reference) & 1 (reference) \\
\hline Yes & 94139 & 90 & $13.0(10.9$ to 15.4$)$ & 1.3 (1.0 to 1.6$)$ & $1.2(0.9$ to 1.5$)$ \\
\hline \multicolumn{6}{|l|}{ Parental educational level: } \\
\hline Low & 28504 & 26 & $12.1(8.1$ to 17.4$)$ & 0.7 (0.5 to 1.1) & $0.8(0.5$ to 1.2$)$ \\
\hline Medium & 278089 & 258 & $12.5(11.0$ to 14.1$)$ & $1.0(0.8$ to 1.3$)$ & $1.1(0.8$ to 1.3$)$ \\
\hline High & 241751 & 147 & & 1 (reference) & 1 (reference) \\
\hline \multicolumn{6}{|l|}{ Child's grade group (quarter): } \\
\hline 1 & 140014 & 134 & 12.9 (10.9 to 15.2$)$ & 1.8 (1.2 to 2.6$)$ & $2.0(1.4$ to 2.8$)$ \\
\hline 2 & 119077 & 81 & $9.2(7.3$ to 11.3$)$ & 1.4 (1.0 to 2.1$)$ & $1.5(1.0$ to 2.2$)$ \\
\hline 3 & 108069 & 44 & $5.5(4.0$ to 7.3 & $1.0(0.6$ to 1.5$)$ & $1.0(0.6$ to 1.5$)$ \\
\hline 4 & 113589 & 43 & 5.1 (3.7 to 6.8 ) & 1 (reference) & 1 (reference) \\
\hline Missing & 13702 & 29 & 29.0 (19.8 to 41.0) & $3.8(2.3$ to 6.2$)$ & $4.5(2.7$ to 7.3$)$ \\
\hline Incomplete & 54270 & 100 & $24.8(20.3$ to 30.0$)$ & $3.0(2.0$ to 4.4$)$ & $3.6(2.5$ to 5.3$)$ \\
\hline \multicolumn{6}{|l|}{ Childhood psychopathology: } \\
\hline No & 541428 & 424 & 10.5 (9.6 to 11.6$)$ & 1 (reference) & 1 (reference) \\
\hline Yes & 7293 & 7 & $13.8(6.2$ to 27.2$)$ & 0.8 (0.4 to 1.6$)$ & $0.8(0.4$ to 1.7$)$ \\
\hline \multicolumn{6}{|l|}{ Total No of indicators: } \\
\hline 0 & 317023 & 175 & $7.4(6.4$ to 8.6$)$ & reference & 1 (reference) \\
\hline 1 & 127348 & 88 & 9.4 (7.1 to 11.5$)$ & 1.3 (1.0 to 1.7$)$ & $1.1(0.9$ to 1.4$)$ \\
\hline 2 & 61962 & 83 & 18.0 (14.1 to 22.4$)$ & 2.5 (1.9 to 3.3$)$ & $1.9(1.4$ to 2.5$)$ \\
\hline$\geq 3$ & 42388 & 85 & 26.9 (21.5 to 33.2$)$ & $3.7(2.9$ to 4.8$)$ & $2.6(1.9$ to 3.4$)$ \\
\hline
\end{tabular}

${ }^{*}$ Crude model.

tAdjusted for year of birth, sex, foreign born parent, parental educational level, parental income, school grades, and childhood psychopathology.

loading for psychiatric disorders, however, attenuated but did not explain the associations between childhood adversity and suicide. This finding is in favour of a social causation hypothesis for the association we found between childhood adversity and suicide.

Although childhood adversity was common in our cohort, it is important to note that most children (58\%) did not experience any adversity, and 41\% (175/431) of suicides during follow-up were in those with no exposure to adversity. Thus, identification of risk factors for suicide in young people other than the adversities we studied remains a challenge but also an opportunity for suicide prevention in the younger age groups. For example, factors such as abuse and neglect, bullying, mood disorders and substance abuse, physical illness, lack of social support, and exposure to peers with 
suicidal behaviour might be important targets for prevention ${ }^{53}$ but were not studied here.

Furthermore, we found that those with a history of exposure to childhood adversity more often performed worse in school and also had a history of childhood psychopathology to a greater extent. In the light of previous evidence that children from adverse family backgrounds tend to show school performance below their potential, based on their cognitive capacity, ${ }^{54}$ programmes aimed at boosting school performance and providing social support to disadvantaged children could prove one promising pathway for improved mental health and suicide prevention. Moreover, a chaotic household seems to increase the suicide risk among young people, and previous findings have identified family support as an important intervention target to decrease suicide risk among anxious young people..$^{55}$ Family support and involvement in intervention for those at risk is another potentially successful pathway. ${ }^{56}$ Lastly, the fact that indicators of childhood adversity often co-occur might have important implications for intervention. Prevention of single indicators among individuals exposed to several is unlikely to have any effects, and universal public health policies aiming to reduce social disadvantage and its impact on children lives are warranted.

Furthermore, the strong associations we found between single childhood adversities and suicide suggest that efforts should also be made to develop selective interventions that effectively alleviate suicide risk in easily identifiable groups at high risk. For example, children exposed to family suicide constitute a relatively small subgroup of all children with childhood adversity in our study but could be easily identified through school, the healthcare system, or social services, all of which are potential arenas for evidence based preventive interventions.

\section{Strengths and limitations}

This study has several strengths, including the large cohort size, the longitudinal population based design, and use of national registers with high completeness and validity. Other studies on childhood adversity and mental health have often been retrospective and based on self reported information, entailing risk for recall bias (for example, under-reporting of childhood adversity). ${ }^{57}$ Despite these strengths, our findings should be interpreted in the context of the following limitations. The range of indicators of childhood adversity is far from exhaustive, and we did not assess the severity, duration, or sequencing of any of these indicators. Furthermore, several of the indicators capture only the most severe cases (parental substance abuse, parental psychiatric disorder, substantial parental criminality), which should be considered when interpreting the results. Moreover, we do not know how adversity might have influenced treatment seeking in young people, which in turn might influence use of mental health services and eventually the risk of suicide. By relying solely on register data, there are indicators that we were not able to study, including abuse and neglect. Both the consistency of our results with other studies and the large cohort with high quality data, however, lends confidence to the validity of our findings.

\section{Conclusion}

In conclusion, this study provides clear evidence that childhood adversities that are common in the general population are associated with an increased risk for suicide in adolescents and young adults. The risk is markedly increased in young people exposed to cumulative adversities. These results emphasise the importance of understanding the social mechanisms of mental health morbidity and suicide and the need for developing effective interventions, aiming to alleviate the risk of suicide in disadvantaged children. This should be done in parallel with wider societal efforts to reduce the size of social disadvantage.

Contributors: All authors are joint senior authors. CB and EB originated the idea, designed the study, and conducted the analyses. All authors interpreted the analyses and critically reviewed and edited the manuscript. CB wrote the manuscript draft, and all authors approved the final version. CB and EB are guarantors.

Funding: This study was supported by grants from the Swedish Society for Medical Research (CB) and the Swedish Council for Working Life and Social Research (grant No 2013-2729, EB). The funders had no role in the analyses interpretation of results or the writing of this manuscript.

Competing interests: All authors have completed the ICMJE uniform disclosure form at www.icmje.org/coi_disclosure.pdf (available on request from the corresponding author) and declare: no other financia relationships with any organisations that might have an interest in the submitted work in the previous three years: no other relationships or activities that could appear to have influenced the submitted work.

Ethical approval: This study was approved by the ethical committee in Stockholm, Sweden (dnrs: 2010/1185-31/1 and 2013/1118-32).

Data sharing: The statistical code is available from the corresponding author. Under Swedish law and ethical approval, patient level data cannot be made available.

Transparency: The lead author affirms that this manuscript is an honest, accurate and transparent account of the study being reported, that no important aspects of the study have been omitted; and that any discrepancies form the study as planned (and, if relevant, registered) have been explained.

This is an Open Access article distributed in accordance with the Creative Commons Attribution Non Commercial (CC BY-NC 4.0) license, which permits others to distribute, remix, adapt, build upon this work non-commercially, and license their derivative works on different terms, provided the original work is properly cited and the use is noncommercial. See: http://creativecommons.org/licenses/by-nc/4.0/.

1 Turecki G, Brent DA. Suicide and suicidal behaviour. Lancet 2016;387:1227-39. doi:10.1016/S0140-6736(15)00234-2.

2 World Health Organization. Preventing suicide: A global imperative. WHO, 2014.

3 Cash SJ, Bridge JA. Epidemiology of youth suicide and suicidal behavior. Curr Opin Pediatr 2009;21:613-9. doi:10.1097/ MOP.0b013e32833063e1

4 Wasserman D, Cheng Q, Jiang GX. Global suicide rates among young people aged 15-19. World Psychiatry 2005;4:114-20.

5 Calear AL, Christensen H, Freeman A, et al. A systematic review of psychosocial suicide prevention interventions for youth. Eur Child Adolesc Psychiatry 2016;25:467-82. doi:10.1007/s00787-015-0783-4.

6 Bruffaerts R, Demyttenaere K, Borges G, et al. Childhood adversities as risk factors for onset and persistence of suicidal behaviour. $\mathrm{Br}$ J Psychiatry 2010;197:20-7. doi:10.1192/bjp.bp.109.074716.

7 Dube SR, Anda RF, Felitti VJ, Chapman DP, Williamson DF, Giles WH. Childhood abuse, household dysfunction, and the risk of attempted suicide throughout the life span: findings from the Adverse Childhood Experiences Study. JAMA 2001;286:3089-96. doi:10.1001/ jama.286.24.3089.

8 Brent DA, Melhem NM, Oquendo M, et al. Familial pathways to early-onset suicide attempt: a 5.6-year prospective study. JAMA Psychiatry 2015;72:160-8. doi:10.1001/jamapsychiatry.2014.2141.

9 Anda RF, Butchart A, Felitti VJ, Brown DW. Building a framework for global surveillance of the public health implications of adverse childhood experiences. Am J Prev Med 2010;39:93-8. doi:10.1016/ j.amepre.2010.03.015

10 Agerbo E, Nordentoft M, Mortensen PB. Familial, psychiatric, and socioeconomic risk factors for suicide in young people: nested case-control study. BMJ 2002;325:74. doi:10.1136/bmj.325.7355.74.

11 Brent DA, Bridge J, Johnson BA, Connolly J. Suicidal behavior runs in families. A controlled family study of adolescent suicide victims. Arch Gen Psychiatry 1996;53:1145-52. doi:10.1001/archpsyc.1996.01830120085015. 
12 Rojas Y, Stenberg SA. Early life circumstances and male suicide--a 30-year follow-up of a Stockholm cohort born in 1953. Soc Sci Med 2010:70:420-7. doi:10.1016/i.socscimed.2009.10.026.

13 Brent DA, Perper JA, Moritz G, et al. Stressful life events, psychopathology, and adolescent suicide: a case control study. Suicide Life Threat Behav 1993;23:179-87.

14 Grøholt B, Ekeberg O, Wichstrøm L, Haldorsen T. Suicide among children and younger and older adolescents in Norway: a comparative study. J Am Acad Child Adolesc Psychiatry 1998;37:473-81. doi:10.1097/00004583-199805000-00008.

15 Björkenstam E, Hjern A, Mittendorfer-Rutz E, Vinnerljung B, Hallqvist J, Ljung R. Multi-exposure and clustering of adverse childhood experiences, socioeconomic differences and psychotropic medication in young adults. PLoS One 2013;8:e53551. doi:10.1371/journal. pone.0053551.

16 Björkenstam E, Burström B, Brännström L, Vinnerljung B, Björkenstam C, Pebley AR. Cumulative exposure to childhood stressors and subsequent psychological distress. An analysis of US panel data. Soc Sci Med 2015;142:109-17. doi:10.1016/j.socscimed.2015.08.006.

17 Afifi TO, Enns MW, Cox BJ, Asmundson GJ, Stein MB, Sareen I. Population attributable fractions of psychiatric disorders and suicide ideation and attempts associated with adverse childhood experiences. Am J Public Health 2008;98:946-52. doi:10.2105/ AJPH.2007.120253.

18 Johnson JG, Cohen P, Gould MS, Kasen S, Brown J, Brook JS. Childhood adversities, interpersonal difficulties, and risk for suicide attempts during late adolescence and early adulthood. Arch Gen Psychiatry 2002;59:741-9. doi:10.1001/archpsyc.59.8.741.

19 Rytilä-Manninen M, Lindberg N, Haravuori H, et al. Adverse childhood experiences as risk factors for serious mental disorders and inpatien hospitalization among adolescents. Child Abuse Negl 2014:38:2021 32. doi:10.1016/j.chiabu.2014.10.008.

20 Enns MW, Cox BJ, Afifi TO, De Graaf R, Ten Have M, Sareen J. Childhood adversities and risk for suicidal ideation and attempts: a longitudinal population-based study. Psychol Med 2006;36:1769-78. doi:10.1017/ S0033291706008646

21 Björkenstam E, Kosidou K, Björkenstam C. Childhood household dysfunction and risk of self-harm: a cohort study of 107518 young adults in Stockholm County. Int J Epidemiol 2016;45:501-11 doi:10.1093/ije/dyw012

22 Bellis MA, Hughes K, Leckenby N, Hardcastle KA, Perkins C, Lowey H. Measuring mortality and the burden of adult disease associated with adverse childhood experiences in England: a national survey. J Public Health (Oxf) 2015;37:445-54. doi:10.1093/pubmed/fdu065.

23 Kelly-Irving M, Lepage B, Dedieu D, et al. Adverse childhood experiences and premature all-cause mortality. Eur J Epidemiol 2013;28:721-34. doi:10.1007/s10654-013-9832-9.

24 Björkenstam E, Dalman C, Vinnerljung B, Weitoft GR, Walder DI, Burström B. Childhood household dysfunction, school performance and psychiatric care utilisation in young adults: a register study of 96399 individuals in Stockholm County. J Epidemiol Community Health 2016;70:473-80. doi:10.1136/jech-2015-206329.

25 Lansford JE, Dodge KA, Pettit GS, Bates JE, Crozier J, Kaplow J. A 12-year prospective study of the long-term effects of early child physical maltreatment on psychological, behavioral, and academic problems in adolescence. Arch Pediatr Adolesc Med 2002;156:82430. doi:10.1001/archpedi.156.8.824

26 Berlin MVB, Hjern A. School performance in primary school and psychosocial problems in young adulthood among care leavers from long term foster care. Child Youth Serv Rev 2011;33:2489-97doi:10.10 16/i.childyouth.2011.08.024

27 Björkenstam C, Weitoft GR, Hjern A, Nordström P, Hallqvist J, Ljung R. School grades, parental education and suicide--a national register-based cohort study. J Epidemiol Community Health 2011;65:993-8. doi:10.1136/jech.2010.117226.

28 Cnattingius S, Ericson A, Gunnarskog J, Källén B. A quality study of a medical birth registry. Scand J Soc Med 1990;18:143-8.

29 Ludvigsson JF, Otterblad-Olausson P, Pettersson BU, Ekbom A. The Swedish personal identity number: possibilities and pitfalls in healthcare and medical research. Eur J Epidemiol 2009;24:659-67. doi:10.1007/s10654-009-9350-y.

30 Ludvigsson JF, Andersson E, Ekbom A, et al. External review and validation of the Swedish national inpatient register. BMC Public Health 2011;11:450. doi:10.1186/1471-2458-11-450.

31 Ludvigsson JF, Almqvist C, Bonamy AK, et al. Registers of the Swedish total population and their use in medical research[published Online First: 2016/01/16]. Eur J Epidemiol 2016;31:125-36. doi:10.1007/ s10654-016-0117-y.

32 Statistics Sweden. Beskrivning av statistiken. Grundskolan: slutbetyg 2014/15 [Description of statistics for year 9 in primary school], 2015.

33 Abel KM, Heuvelman HP, Jörgensen L, et al. Severe bereavement stress during the prenatal and childhood periods and risk of psychosis in later life: population based cohort study. BMJ 2014;348:f7679. doi:10.1136/bmj.f7679.
34 Siegenthaler E, Munder T, Egger M. Effect of preventive interventions in mentally ill parents on the mental health of the offspring: systematic review and meta-analysis. J Am Acad Child Adolesc Psychiatry 2012;51:8-17.e8. doi:10.1016/j.jaac.2011.10.018.

35 Farrington D, Welsh B. Saving Children from a Life of Crime.Oxford University Press Inc, 2007.

36 Ringbäck Weitoft G, Hjern A, Batljan I, Vinnerljung B. Health and social outcomes among children in low-income families and families receiving social assistance--a Swedish national cohort study. Soc Sci Med 2008;66:14-30. doi:10.1016/i.socscimed.2007.07.031

37 Weitoft GR, Hjern A, Haglund B, Rosén M. Mortality, severe morbidity, and injury in children living with single parents in Sweden: a population-based study. Lancet 2003;361:289-95. doi:10.1016/ S0140-6736(03)12324-0.

38 Wood D, Halfon N, Scarlata D, Newacheck P, Nessim S. Impact of family relocation on children's growth, development, school function, and behavior. JAMA 1993:270:1334-8, doi:10.1001/ jama.1993.03510110074035.

39 Wilcox HC, Kuramoto SJ, Lichtenstein P, Långström N, Brent DA, Runeson B. Psychiatric morbidity, violent crime, and suicide among children and adolescents exposed to parental death. J Am Acad Child Adolesc Psychiatry 2010;49:514-23, quiz 530

40 Linsley KR, Schapira K, Kelly TP. Open verdict v. suicide - importance to research. Br J Psychiatry 2001:178:465-8 doi:10.1192/bip.178.5.465.

41 Kosidou K, Hellner-Gumpert C, Fredlund P, et al. Immigration, transition into adult life and social adversity in relation to psychological distress and suicide attempts among young adults. PLoS One 2012;7:e46284. doi:10.1371/journal.pone.0046284.

42 Kuh D, Power C, Blane D, et al. Socioeconomic pathways between childhood and adult health. In: Kuh D, Ben-Shlomo Y, eds. A Life Course Approach to Chronic Disease Epidemiology.Oxford University Press, 2004doi:10.1093/acprof:0so/9780198578154.003.0016

43 Vinnerljung B, Brännström L, Hjern A. Disability pension among adult former child welfare clients: A Swedish national cohort study. Child Youth Serv Rev 2015;56:169-76doi:10.1016/j.childyouth.2015.07.001

44 O'Connor RC, Nock MK. The psychology of suicidal behaviour. Lancet Psychiatry 2014;1:73-85. doi:10.1016/S2215-0366(14)70222-6.

45 Sørensen HJ, Mortensen EL, Wang AG, Juel K, Silverton L, Mednick SA. Suicide and mental illness in parents and risk of suicide in offspring: birth cohort study. Soc Psychiatry Psychiatr Epidemiol 2009;44:74851. doi:10.1007/s00127-009-0495-5.

46 Hollingshaus MS, Smith KR. Life and death in the family: early parental death, parental remarriage, and offspring suicide risk in adulthood. Soc Sci Med 2015;131:181-9. doi:10.1016/j.socscimed.2015.02.008.

47 McGirr A, Renaud J, Bureau A, Seguin M, Lesage A, Turecki G. Impulsive-aggressive behaviours and completed suicide across the life cycle: a predisposition for younger age of suicide. Psychol Med 2008:38:407-17. doi:10.1017/S0033291707001419.

48 Brent DAMJ, Mann JJ. Family genetic studies, suicide, and suicidal behavior. Am J Med Genet C Semin Med Genet 2005;133C:13-24. doi:10.1002/ajmg.c.30042.

49 Borges G, Angst J, Nock MK, Ruscio AM, Kessler RC. Risk factors for the incidence and persistence of suicide-related outcomes: a 10-year follow-up study using the National Comorbidity Surveys. J Affect Disord 2008·105.25-33 doi:10.1016/j.jad.2007.01.036.

50 Björkenstam E, Dalman C, Vinnerljung B, et al. Childhood household dysfunction, school performance and psychiatric care utilization in young adults: a register study of 96,399 individuals in Stockholm County. J Epidemiol Community Health 2015

51 Kessler RC, McLaughlin KA, Green JG, et al. Childhood adversities and adult psychopathology in the WHO World Mental Health Surveys. Brj Psychiatry 2010;197:378-85. doi:10.1192/bjp.bp.110.080499.

52 Hawton K, van Heeringen K. Suicide. Lancet 2009;373:1372-81. doi:10.1016/S0140-6736(09)60372-X

53 Arango A, Opperman KJ, Gipson PY, King CA. Suicidal ideation and suicide attempts among youth who report bully victimization, bully perpetration and/or low social connectedness. J Adolesc 2016;51:19 29. doi:10.1016/i.adolescence.2016.05.003.

54 Vinnerljung B, Berlin M, Hjern A. Skolbetyg, utbildning och risker för ogynnsam utveckling hos barn [School performance, education, and risks for unfavourable development among children]. In: National Board of Health and Welfare, ed. Social rapport 2010 [Social Report]. Edita Västra Aros, 2010:228-66.

55 Machell KA, Rallis BA, Esposito-Smythers C. Family environment as a moderator of the association between anxiety and suicidal ideation. J Anxiety Disord 2016;40:1-7. doi:10.1016/j.janxdis.2016.03.002.

56 Garland AF, Zigler E. Adolescent suicide prevention. Current research and social policy implications. Am Psychol 1993;48:169-82. doi:10.1037/0003-066X.48.2169.

57 Hardt J, Rutter M. Validity of adult retrospective reports of adverse childhood experiences: review of the evidence. J Child Psychol Psychiatry 2004;45:260-73. doi:10.1111/j.1469-7610.2004.00218.x.

Appendix 1: Supplementary table 